Article

\title{
Assessing Movement Quality in Youth Footballers: The Relationship between Hip and Lower Limb Movement Screen and Functional Movement Screen
}

\author{
Pawel Linek 1,2,*(D), Paul E. Muckelt ${ }^{2,3}$, Damian Sikora ${ }^{1,4}$, Nadine Booysen ${ }^{2,3,5}$ and Maria Stokes ${ }^{2,3,5}$ (D) \\ 1 Institute of Physiotherapy and Health Sciences, Musculoskeletal Elastography and Ultrasonography \\ Laboratory, The Jerzy Kukuczka Academy of Physical Education, 40-065 Katowice, Poland; \\ damiansikora21@o2.pl \\ 2 School of Health Sciences, University of Southampton, Southampton SO17 1BJ, UK; \\ P.Muckelt@soton.ac.uk (P.E.M.); n.c.l.booysen@soton.ac.uk (N.B.); M.Stokes@soton.ac.uk (M.S.) \\ 3 Centre for Sport, Exercise and Osteoarthritis Research Versus Arthritis, Southampton SO17 1BJ, UK \\ 4 PROF-MED Rehabilitation Center Damian Sikora, 41-300 Dabrowa Górnicza, Poland \\ 5 Southampton National Institute for Health Research Biomedical Research Centre, \\ Southampton SO16 6YD, UK \\ * Correspondence: p.linek@awf.katowice.pl or linek.fizjoterapia@vp.pl; Tel.: +48-661768601
}

check for updates

Citation: Linek, P.; Muckelt, P.E.; Sikora, D.; Booysen, N.; Stokes, M. Assessing Movement Quality in Youth Footballers: The Relationship between Hip and Lower Limb Movement Screen and Functional Movement Screen. Appl. Sci. 2021, 11, 9298. https://doi.org/10.3390/ app11199298

Academic Editor: Antonio Parziale

Received: 7 August 2021

Accepted: 29 September 2021

Published: 7 October 2021

Publisher's Note: MDPI stays neutral with regard to jurisdictional claims in published maps and institutional affiliations.

Copyright: (c) 2021 by the authors. Licensee MDPI, Basel, Switzerland. This article is an open access article distributed under the terms and conditions of the Creative Commons Attribution (CC BY) license (https:/ / creativecommons.org/licenses/by/ $4.0 /)$.

\begin{abstract}
The Hip and Lower Limb Movement Screen (HLLMS) was developed to detect altered movement patterns and asymmetry specifically related to hip, pelvic, and lower limb movement control, as the other tools, such as the Functional Movement Screen (FMS), lacked focus on the hip and pelvic area. Both screening tools contain symmetrical and asymmetrical motor tasks which are based on observation of different aspects of each task performance. One motor task is in both screening tools. Therefore, they have some common features. The present study aimed to assess the relationship between the HLLMS and FMS performance in youth football players. The study included 41 elite male football (soccer) players (age: $15.6 \pm 0.50$ years), and the HLLMS and FMS scores were analyzed by assessing Spearman's rank correlation. The FMS total score and the FMS MOVE were moderately correlated with the HLLMS total score $(\mathrm{R}=-0.54 ;-0.53$, respectively). The FMS rotatory stability task was moderately correlated with the HLLMS small knee bend with the trunk rotation task $(\mathrm{R}=-0.50)$. The FMS deep squat task was moderately correlated with the HLLMS deep squat task $(\mathrm{R}=-0.46)$. The FMS hurdle step was weakly correlated with two of the HLLMS tasks: standing hip flexion $(\mathrm{R}=-0.37)$ and hip abduction with external rotation $(\mathrm{R}=-0.34)$. There were no other relationships found ( $p>0.05$ ). Out of the seven FMS tasks, only one asymmetrical (trunk rotary stability) and one symmetrical (deep squat) task were moderately related to the newly developed HLLMS tool contributing moderate relationship between the FMS total score and the HLLMS total score. Other FMS tasks were weakly or unrelated with the HLLMS. These findings indicate that these two screening tools mainly assess different aspects of movement quality in healthy youth football players.
\end{abstract}

Keywords: movement screening; movement quality; football; youth; hip and pelvis

\section{Introduction}

Poor quality movement control in the hip and pelvic region has been shown in biomechanical studies to affect joints lower in the kinetic chain, contributing to abnormal loading [1] and injuries at the knee, e.g., anterior cruciate ligament tears [2,3]. The ability to assess hip and pelvic control in the clinical or field situation could help guide exercise strategies to improve muscular control appropriately. Movement screening tools have gained popularity, which includes movement tests mainly focused on predicting injury risk and/or guiding injury prevention programmes [4]. Current movement screening tools do not focus on hip and pelvic movement dysfunction or examine the influence of 
motor control exercises on hip and pelvic movement quality [5]. Therefore, the present study examined the relationship between two movement screening tools to investigate movement quality and their ability to assess hip and pelvic control.

The functional movement screen (FMS) seems to be one of the most well-known movement screening tools. The FMS was designed to identify limb asymmetries, assess mobility and stability within the whole-body kinetic chain, and to detect poor-quality locomotor patterns during specific movement tasks [6,7]. The FMS has been shown to be valid and reliable $[8,9]$ and is mainly used to assess athletes' risk of becoming injured, although systematic reviews have presented conflicting opinions about the ability of the FMS to predict injury $[8,10,11]$. It may be that the ability of the FMS to predict injury is limited to specific sports or types of injuries, but more homogeneous studies in terms of type of sport and/or injury are needed.

Altered movement patterns and/or asymmetry, which can be detected during movement screening tests (e.g., FMS), may contribute to repetitive abnormal loading on joints, making them vulnerable to long-term damage. For example, increased hip medial rotation and adduction are associated with knee valgus [12], which has been linked to anterior cruciate ligament injury risk [2]. In addition, some authors [13,14] have suggested that repetitive altered joint loading contributes to the development of osteoarthritis (OA). Thus, prevention strategies to improve and/or correct altered movement patterns could be considered in long-term management to potentially prevent the development of OA, since athletes are at an increased risk of subsequent OA [15].

This is particularly prevalent in football where higher rates of hip and groin injuries were among sports included in an epidemiological study [16]. The incidence of hip and groin pain in youth football was $14-22 \%[17,18]$. Youth athletes are also at increased risk of later OA due to altered joint loading and injury $[15,19]$. Due to high injury rates and joint loading of the hip, knee, and ankle in youth football players, it would be useful to have movement screening tools that are sensitive to altered movement patterns or asymmetries of the hip and lower limbs. The FMS is not useful for assessing the functional status in hip dysfunction in athletes [20]. Similarly, Linek et al. [21] found that the FMS rating was comparable in healthy football players and football players with mild hip or groin symptoms. These results suggest that the FMS does not discriminate between altered movement patterns in lower limb joints among footballers, so a more sensitive tool is needed.

The recently developed Hip and Lower Limb Movement Screen (HLLMS) detects altered movement patterns and asymmetry, specifically of the hip, pelvis and lower limbs [5]. The HLLMS has been shown to have excellent intra-rater reliability and strong inter-rater reliability in adolescent male football players [5]. To date, two aspects of the HLLMS validity (criterion validity and sensitivity to change) have been indicated [22]. Additionally, preliminary observations show that tasks included in the HLLMS can detect movement control impairments in athletes $[23,24]$. The HLLMS is mainly intended to inform neuromuscular exercises to improve muscle control and movement quality specifically to the pelvic region and lower limbs [5]. Thus, the aim of the present study was to investigate the relationship between the FMS and the HLLMS performance in youth football players. Both tests are analyzed using a composite score (sum of all motor tasks), but each of the tasks of the HLLMS may also be analyzed separately. A factorial analysis has shown that the FMS is not a unitary construct [25], meaning that using the summed score may be misleading relative to the individual item scores. In fact, the FMS and the HLLMS contain symmetrical and asymmetrical motor tasks which are based on observation of different aspects of each task performance. One motor task (the deep squat) is in both screening tools. Therefore, both screening tests have some common features. Thus, the comparison between the results from these two assessment tools is needed to ensure they were testing different aspects of movement control and to provide further evidence of the need for the HLLMS, as it has been suggested that the FMS is not appropriate for assessing hip dysfunction [20]. Taking into account that the FMS does not appear to detect abnormal 
movement patterns specifically of the lower limbs, and that the HLLMS was developed specifically to detect abnormal movement patterns of the hips, pelvis, and lower limbs, we hypothesized that the relationship would be weak or even absent in youth footballers.

\section{Materials and Methods}

\subsection{Setting and Study Design}

This study was conducted at a professional football club in the Silesian region of Poland. The design was a cross-sectional, observational single-group study of two assessment tools to examine their relationship. All outcomes were measured by two experienced physiotherapists blinded to the study aim. Measurements were conducted in two separate rooms; the physiotherapists were only informed that the results of both screening tools would be used for training purposes. All measurements were taken during the same day in random order. The time taken to complete each screening tool ranged between 10 and $20 \mathrm{~min}$. The study was conducted in accordance with the Declaration of Helsinki and was approved by the local medical ethics committee (Ethics Approval number: 4/2017). All participants and their parents and/or legal guardians received oral and written information about all procedures and gave written, informed consent to participate. The two movement quality assessments being investigated are observational tools.

\subsection{Sample}

Forty-one male footballers (age: $15.6 \pm 0.50$; range from 15 to 16 years of age) were selected using convenience sampling from an elite youth football club. Their characteristics were: body mass: $65.6 \pm 8.47 \mathrm{~kg}$; body height: $176.5 \pm 6.76 \mathrm{~cm}$; BMI: $21 \pm 1.83 \mathrm{~kg} / \mathrm{m}^{2}$; football participation: $7.55 \pm 1.90$ years. The exclusion criteria were: (a) acquired an injury that prevented participation in training or competition for longer than one week during the four months prior to the examination; (b) any prior surgery; (c) inability to perform all subtests in either of the two movement screens used (FMS or HLLMS); (d) reluctant or unable to follow the instruction during the tests.

\subsection{Functional Movement Screen}

The FMS consists of seven motor task tests: shoulder mobility, rotary stability, hurdle step, deep squat, in-line lunge, active straight-leg raise, and trunk stability push-up [6,7]. The FMS has excellent inter-rater and intra-rater reliability. The intraclass correlation coefficient for intra-rater reliability was 0.81 (95\% CI, 0.69-0.92) and for inter-rater reliability was 0.81 (95\% CI, 0.70-0.92) [8]. The performance on all tasks was assessed by observing each motor task using a scale from 0 to 3 , where 0 indicates pain during movement, 1 indicates the inability to perform the motor pattern, 2 indicates execution of the locomotor pattern with some compensatory adjustments, and 3 indicates the appropriate execution of the locomotor pattern [6,7]. Each task was performed twice, and the better result was used for further analysis [6,7]. In the case of tasks completed on the left and right sides, the lower score was used in the calculation of the total FMS score. Three separate categories of

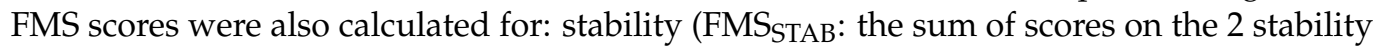
tests, trunk stability push-up and rotatory stability); flexibility (FMS FLEX: the sum of scores on the 2 mobility tests, shoulder mobility and active straight-leg raise); and movement

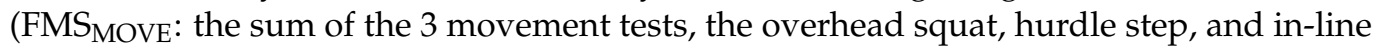
lung). The three motor tasks included in the $\mathrm{FMS}_{\mathrm{MOVE}}$ are more functional and include movement that may challenge the hip and pelvic movement. From this perspective, it was decided to categorize the FMS motor tasks, and analyze the potential relationship of grouped tasks. The same FMS categories were used by Portas et al. [26] and Linek et al. [21] in studies on youth footballers. The FMS data were collected by an experienced (8 years) and qualified physiotherapist, who attended the FMS course and regularly used the screen. 


\subsection{Hip and Lower Limb Movement Screen}

The HLLMS consists of five motor task tests: a small knee bend (SKB), standing hip flexion $0-110^{\circ}$, hip abduction with lateral rotation (in side lying), SKB with trunk rotation and deep squat. The performance of each task was assessed by observing the presence or absence of a deviation from the benchmark criteria using a dichotomous scale ('yes' meaning that the movement fault is present and is scored ' 1 '; 'no' that the movement fault is absent and is scored ' 0 '. A higher score therefore indicates more movement faults). The entire HLLMS includes 21 yes or no questions, with most tests (four) conducted unilaterally except for the deep squat which is observed bilaterally. In further analysis the combined score from each task for both the left and right side $(19 \times 2$ questions $)$ and bilateral task (2 questions), and total HLLMS score (maximum 40 movement faults) were used [5]. The HLLMS total score is the summed positive answers to all questions (Table 1).

Table 1. The Hip and Lower Limb Movement screen scoring-more details in Booysen et al.'s study [5].

\begin{tabular}{lccc}
\hline Test & Number of Criteria & \multicolumn{2}{c}{ Total Possible Score ${ }^{\mathbf{1}}$} \\
\hline & 5 & Right & Left \\
SKB & 5 & 5 & 5 \\
Standing hip flexion & 5 & 5 & 5 \\
Hip abduction lateral rotation & 4 & 5 & 5 \\
SKB with trunk rotation & 2 & 4 & 2 \\
Deep squat & \multicolumn{3}{c}{4} \\
\hline Total Score & \multicolumn{3}{l}{} \\
SKB-A small knee bend; ${ }^{1}$ The total possible score of movement faults.
\end{tabular}

The HLLMS has been shown to have an excellent intra-rater reliability (percentage agreement (PA) 96\% and first-order coefficient (AC1) 0.93), and a strong inter-rater reliability (PA 88\%; AC1 0.82) in youth male footballers [5]. A detailed protocol, tasks descriptions, and benchmark assessment criteria (questions) are given elsewhere [5]. In the present study, the HLLMS data were collected by an experienced (10 years) and qualified physiotherapist (who also attended the FMS course and had $20 \mathrm{~h}$ of familiarization with the HLLMS) who was not informed of this study aim. The physiotherapist performed two trials (one from the front and one from the side) to observe and collect all the movement faults.

\subsection{Statistical Analysis}

Given the nature of the scoring systems, good movement quality is indicated by a higher total value on the FMS and a lower total value on the HLLMS. Due to the dichotomous scale of tasks included in the HLLMS and the FMS, a non-parametric Spearman's rank correlation analysis was applied and interpreted as negligible (0.00-0.10), weak (0.10-0.39), moderate (0.40-0.69), strong (0.70-0.89), and very strong (0.90-1.00), according to Schober et al. [27]. A monotonic association between the HLLMS and the FMS was evaluated. All statistical analyses were performed on 41 participants with the Statistica 13.1PL software and $p$-values $<0.05$ were considered significant.

\section{Results}

\subsection{Total Score}

The FMS total score and the FMS ${ }_{\text {MOVE }}$ were moderately $(\mathrm{R}=-0.54 ;-0.53$, respectively) correlated with the HLLMS total score. In both cases, footballers with a lower FMS score received a higher number of positive answers in the HLLMS. There were no significant correlations $(p>0.06)$ between the HLLMS total score and the FMS FLEX and the FMS $_{\text {STABIL }}$ (Figure 1). 

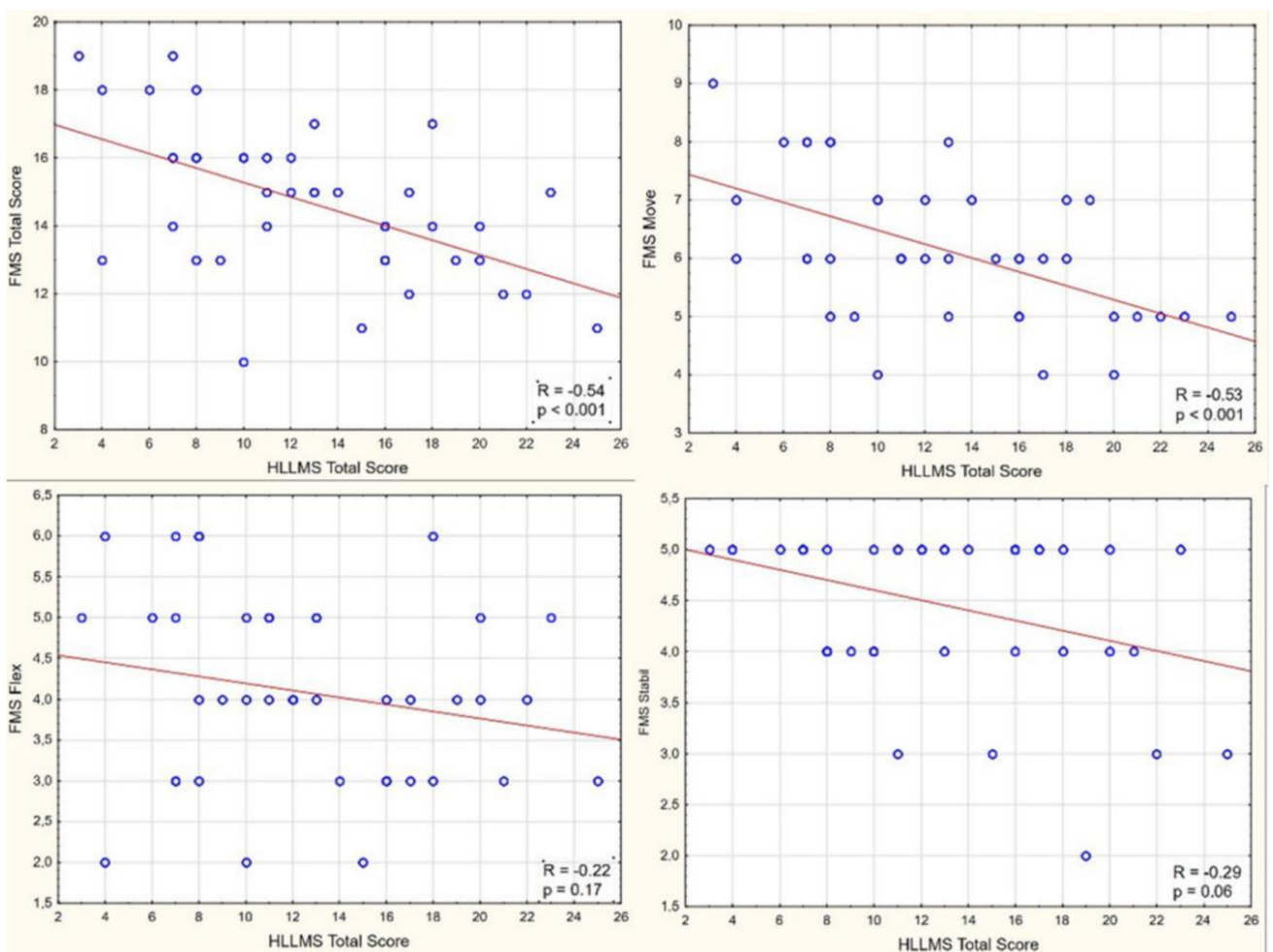

Figure 1. Total score of the Hip and Lower Limb Movement Score (HLLMS) in relation to total score of the Functional Movement Screen (FMS) and sub-scores of stability, flexibility, and movement (data on 41 footballers-some participants obtained the same pair of HLLMS and FMS scores; therefore, their points are superimposed).

\subsection{Asymmetrical Tasks}

Regarding tasks performed separately for the right and left sides of the body, the composite score of each task from the FMS was correlated with the composite score of each task from the HLLMS. The results showed that the rotatory stability test (FMS) was moderately correlated $(\mathrm{R}=-0.50)$ with the SKB in the trunk rotation task (HLLMS; Table 1).

A weak correlation was found between the hurdle step (FMS) and two of the HLLMS tasks: standing hip flexion $(\mathrm{R}=-0.37)$ and hip abduction with external rotation $(\mathrm{R}=-0.34)$. There were no correlations $(p>0.05)$ between the FMS in-line lunge test, shoulder mobility test, and the HLLMS SKB test (Table 2 and Figure S1).

Table 2. Spearman correlation for combined score of asymmetrical tasks.

\begin{tabular}{|c|c|c|c|c|c|}
\hline & & \multicolumn{4}{|c|}{ HIP AND LOWER LIMB MOVEMENT SCREEN } \\
\hline & & $\begin{array}{l}\text { Standing Hip } \\
\text { Flexion }\end{array}$ & $\begin{array}{l}\text { Hip Abduction with } \\
\text { Lateral Rotation }\end{array}$ & Small Knee Bend & $\begin{array}{l}\text { Small Knee Bend } \\
\text { with Trunk Rotation }\end{array}$ \\
\hline \multirow{5}{*}{$\begin{array}{l}\text { FUNCTIONAL } \\
\text { MOVEMENT } \\
\text { SCREEN }\end{array}$} & In-line lunge & $\begin{array}{c}\mathrm{R}=-0.19 \\
p=0.24\end{array}$ & $\begin{array}{l}\mathrm{R}=0.01 \\
p=0.93\end{array}$ & $\begin{array}{c}\mathrm{R}=-0.28 \\
p=0.08\end{array}$ & $\begin{array}{c}\mathrm{R}=-0.15 \\
p=0.33\end{array}$ \\
\hline & Active straight-leg raise & $\begin{array}{c}\mathrm{R}=-0.13 \\
p=0.42\end{array}$ & $\begin{array}{c}\mathrm{R}=-0.02 \\
p=0.91\end{array}$ & $\begin{array}{c}\mathrm{R}=-0.08 \\
p=0.60\end{array}$ & $\begin{array}{c}\mathrm{R}=-0.25 \\
p=0.12\end{array}$ \\
\hline & Hurdle step & $\begin{aligned} \mathrm{R} & =-0.37 \\
p & =0.02^{*}\end{aligned}$ & $\begin{aligned} \mathrm{R} & =-0.34 \\
p & =0.03^{*}\end{aligned}$ & $\begin{array}{c}\mathrm{R}=-0.22 \\
p=0.17\end{array}$ & $\begin{array}{c}\mathrm{R}=-0.20 \\
p=0.22\end{array}$ \\
\hline & Shoulder mobility & $\begin{array}{c}\mathrm{R}=-0.17 \\
p=0.29\end{array}$ & $\begin{array}{c}\mathrm{R}=-0.03 \\
p=0.87\end{array}$ & $\begin{array}{c}\mathrm{R}=-0.11 \\
p=0.49\end{array}$ & $\begin{array}{c}\mathrm{R}=-0.12 \\
p=0.44\end{array}$ \\
\hline & Trunk rotary stability & $\begin{array}{c}\mathrm{R}=-0.17 \\
p=0.30\end{array}$ & $\begin{array}{l}\mathrm{R}=0.01 \\
p=0.96\end{array}$ & $\begin{array}{c}\mathrm{R}=-0.26 \\
p=0.10\end{array}$ & $\begin{array}{l}\mathrm{R}=-0.50 \\
p=0.001 *\end{array}$ \\
\hline
\end{tabular}

${ }^{*} p<0.05 ; \mathrm{R}$-Spearman's rank correlation; $p$-significance value. 


\subsection{Symmetrical Tasks}

A deep squat task was performed in both the FMS and HLLMS. The FMS deep squat test was moderately $(R=-0.46)$ correlated with the HLLMS deep squat test (Table 3 and Figure S2). The FMS trunk stability push-up was not correlated $(p=0.34)$ with the HLLMS deep squat test.

Table 3. Spearman correlation for symmetrical tasks.

\begin{tabular}{|c|c|c|}
\hline & & HIP AND LOWER LIMB MOVEMENT SCREEN \\
\hline & & Deep Squat \\
\hline \multirow{2}{*}{ 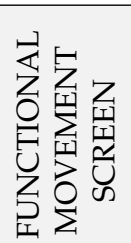 } & Deep squat & $\begin{array}{l}\mathrm{R}=-0.46 \\
p=0.003\end{array}$ * \\
\hline & $\begin{array}{c}\text { Trunk } \\
\text { stability } \\
\text { push-up }\end{array}$ & $\begin{array}{l}\mathrm{R}=0.15 \\
p=0.34\end{array}$ \\
\hline
\end{tabular}

\section{Discussion}

The aim of the present study was to assess the relationship between the two movement screening tools (FMS and HLLMS) in youth football players. This study found that out of all asymmetrical tasks: (1) two pairs of tasks were moderately correlated (FMS trunk rotary stability was correlated with the HLLMS SKB with trunk rotation), (2) two HLLMS tasks (standing hip flexion and hip abduction with lateral rotation) were weakly related with one FMS task (hurdle step), and (3) four FMS tasks (in-line lunge, active straight-leg raise, and shoulder mobility) and one HLLMS task (SKB) were not related. Of the symmetrical tasks, only the deep squat from FMS was moderately correlated with the deep squat from HLLMS. Analyses of total scores for the two assessment tools found that FMS total score

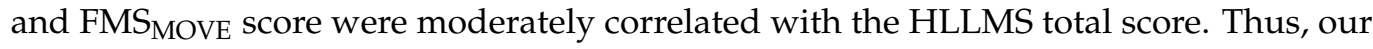
preliminary hypothesis that the relationship between the FMS and the HLLMS should be weak or even absent was not fully achieved. However, (a) most (four out of seven) FMS tasks were not related to the HLLMS at all (three asymmetrical and one symmetrical) and (b) the moderate relationship between both screening tools was caused directly by two pairings between asymmetrical trunk rotary stability (FMS) and the SKB with trunk rotation (HLLMS) as well as the symmetrical deep squat tasks from the two assessment tools.

Although the deep squat was analyzed in different ways by the FMS and the HLLMS (different factors were assessed), a moderate relationship should not be surprising. Movement screening tests are generally intended to assess the movement quality and performance, and to detect altered movement patterns. It could therefore be expected that when performing the same movement task (deep squat), similar outcomes will be reached. While the criteria used may differ between the two tests, the overall movement outcome is similar. As an example, if the thigh (femur) fails to reach horizontal with the floor during the HLLMS deep squat protocol, it will be highly possible that the deep squat movement contains compensation/imperfection according to the FMS protocol. In turn, the rotatory stability test (FMS) requires multi-plane stability of the trunk in conjunction with synchronized motion of the upper and lower extremities [6,7]. Agresta et al. [28] demonstrated that athletes with compensation/imperfection during the rotatory stability FMS task present reduced control of the trunk, pelvis, and hip muscles. A review of the biomechanical and clinical studies indicated that impaired muscular control of the hip, pelvis, and trunk can affect joint mechanics in the lower kinetic chain [1], triggering injuries such as anterior cruciate ligament tears [2], iliotibial band syndrome [29], and patellofemoral joint pain [3,30]. In addition, movement disorders exist in people with femoroacetabular impingement syndrome [13,31-35] and patellofemoral pain [36,37]. The SKB with trunk rotation (the HLLMS task) is described as a test assessing relative stiffness (restrictions) [38] of thoracolumbar rotation under proper pelvic control, and evaluating the 
ability to actively dissociate and control hip rotation independently of trunk rotation [39]. Thus, the rotatory stability test (FMS) and the SKB with trunk rotation (the HLLMS) are intended to detect altered movement quality caused by impaired control in the pelvic region. This may explain the moderate relationship between both the FMS and HLLMS tasks.

Other FMS tasks were weakly (the hurdle step) or not (in-line lunge, active straight-leg raise, shoulder mobility, and trunk stability push-up) related with tasks included in the newly developed HLLMS tool. The hurdle step is used to assess functional mobility and stability of lower limb joints, whereas shoulder mobility and trunk stability push-ups are used to assess the shoulder range of motion and trunk stability during upper-extremity motion, respectively [6,7]. Thus, in the present study, the correlation results were expected. It may only be surprising that no relationship was detected between the in-line lunge (FMS) task and the HLLMS tasks, as the in-line lunge by Cook et al. [6,7] is described as assessing hip and ankle mobility and stability, quadriceps flexibility, and knee stability. Considering that the HLLMS was developed to specifically assess control of the hip, pelvis, and lower limb joints [5], a certain degree of relationship with the in-line lunge (FMS) was expected.

Movement screening tools are characterized by: (a) assessment of movement quality [11]; (b) assessment of physical performance; and (c) identifying painful movement during movement tasks [6,7]. Additionally, it may be worth developing screening tools considering a targeted body part (movement screening tools could be created concerning a specific part of the body). Studies have shown that the FMS is not sensitive for detecting altered movement patterns in lower limb joints of footballers [21,40,41]. It may be partly due to the FMS containing some tasks not directly related to the lower limb, such as the shoulder mobility or the trunk stability push-up. In addition, the FMS lacks unilateral weight-bearing tasks, which are typical in sports [42], and seems more likely to show compensations relevant to bilateral tasks [43]. From this perspective, development of the HLLMS to focus on altered movement patterns and asymmetry, specifically of the pelvis and lower limbs, was warranted, because of the high incidence of hip and groin pain in injuries in athletes [15-17]. The HLLMS does not require any equipment, so it is therefore quick, easy, and cheap to use. It can also be used as an assessment in return to play, by conducting testing at the start of a season then following injuries. Additionally, the HLLMS is useful to detect modifiable movement compensations and direct referral for primary, secondary, and tertiary prevention in the context of injury and OA [5].

The present study had a number of limitations. Firstly, the present findings may only be applied to the group examined (male elite adolescent football players) and generalization to athletes involved in other sports or to female footballers cannot be assumed. Secondly, the study included a relatively small sample size, although other studies using the FMS and/or functional tests used similar sample sizes [21,28,44-47]. Thirdly, although the HLLMS showed very good intra-rater and inter-rater reliability in youth male football players [5], the reliability of the assessor conducting the HLLMS protocol for this study was not examined. However, the HLLMS data were collected by an experienced and qualified physiotherapist (who also attended FMS course) who was not informed of this study aim. To minimize bias being introduced during the data collection process, the FMS and the HLLMS data were collected by two separate raters, ensuring the therapists collecting the data were not aware of previous FMS/HLLMS scores, preventing the investigator's test interpretation being influenced. However, we are unsure whether past experience with the FMS of the physiotherapist assessing the HLLMS may affect the study results in some way. Automatic systems used to assess HLLMS and FMS may be needed in order to avoid bias potentially introduced by the raters. Previous research has been conducted to create an automated system to score the FMS in order to make the tool more objective [48-50]. However, the results were inconclusive. In turn, the HLLMS was only analyzed against 3D motion analysis for a validation purpose [22], but not to automate the scoring of the HLLMS. It may be worthwhile to conduct future research to see if the HLLMS can be automated to improve raters' scores, avoiding bias, while ensuring that the automatization process does not affect the nature of the screening tools. Screening tools should still be 
easily administered to large groups, cost-effective and easily adaptable to various sports and occupation environments [11]. Fourthly, the present study only included healthy athletes (they participated in training or competition for the four months prior to the examination). Theoretically, it is possible that the relationship between the FMS and the HLLMS may be different in symptomatic participants.

\section{Conclusions}

Out of the seven FMS tasks, only one asymmetrical (trunk rotary stability) and one symmetrical (deep squat) task were moderately related to the newly developed HLLMS tool contributing a moderate relationship between the FMS total score and the HLLMS total score. Other FMS tasks were weakly related or unrelated with the HLLMS. This suggests that the two screening tools assess different aspects of movement quality and performance in healthy youth football players. The purpose of the HLLMS is to use the movement quality assessment outcome to prescribe targeted motor control exercises. Practically, it could be used in a clinical setting and on the field for primary prevention to protect healthy people, secondary prevention to prevent re-injury or overuse, and tertiary prevention to guide management of $\mathrm{OA}$ and reduce its impact on function and joint longevity, delaying or preventing joint surgery and improving the quality of life.

Several potential applications of the HLLMS should now be investigated in various cohorts of different ages, physical activity, sporting groups, and genders to examine the utility of the screen for assessing movement quality and informing exercise interventions to improve movement control. It is also worth considering whether the HLLMS can be automated to avoid bias without negative effects on the nature of this screening tool.

Supplementary Materials: The following are available online at https:/ / www.mdpi.com/article / 10.3390/app11199298/s1, Figure S1: Asymmetrical tasks of the Hip and Lower Limb Movement Score in relation to asymmetrical tasks of the Functional Movement Screen, Figure S2: Symmetrical tasks of the Hip and Lower Limb Movement Score in relation to symmetrical tasks of the Functional Movement Screen.

Author Contributions: Conceptualization, P.L., M.S. and N.B.; methodology, P.L. and N.B.; validation, P.E.M.; formal analysis, P.L. and M.S.; investigation, P.L. and D.S.; resources, D.S.; data curation, P.L. and D.S.; writing—original draft preparation, P.L.; writing—review and editing, P.E.M., D.S., N.B. and M.S.; visualization, D.S. and P.L.; supervision, P.L. and M.S.; project administration, P.L. and D.S.; funding acquisition, D.S. All authors have read and agreed to the published version of the manuscript.

Funding: This research received no external funding.

Institutional Review Board Statement: The study was designed in accordance with the Declaration of Helsinki and approved by the local medical ethics committee (Ethics Approval number: 4/2017).

Informed Consent Statement: Informed consent was obtained from all subjects involved in the study.

Data Availability Statement: The data presented in this study are available on request from the corresponding author.

Acknowledgments: The authors thank the participants for their time, and the coaches and staff at their club for helping with the recruitment of players and logistics in carrying out the project.

Conflicts of Interest: There are no conflict of interest in the present study and the study was not funded by any external bodies.

\section{References}

1. Reiman, M.P.; Bolgla, L.A.; Lorenz, D. Hip functions influence on knee dysfunction: A proximal link to a distal problem. J. Sport Rehabil. 2009, 18, 33-46. [CrossRef] [PubMed]

2. Hewett, T.E.; Myer, G.D.; Ford, K.; Heidt, R.S.; Colosimo, A.J.; McLean, S.G.; Bogert, A.V.D.; Paterno, M.V.; Succop, P. Biomechanical measures of neuromuscular control and valgus loading of the knee predict anterior cruciate ligament injury risk in female athletes: A prospective study. Am. J. Sports Med. 2005, 33, 492-501. [CrossRef] [PubMed] 
3. Powers, C.M. The influence of abnormal hip mechanics on knee injury: A biomechanical perspective. J. Orthop. Sports Phys. Ther. 2010, 40, 42-51. [CrossRef] [PubMed]

4. Chimera, N.J.; Warren, M. Use of clinical movement screening tests to predict injury in sport. World J. Orthop. 2016, 7, $202-217$. [CrossRef]

5. Booysen, N.; Wilson, D.A.; Lewis, C.L.; Warner, M.B.; Gimpel, M.; Mottram, S.; Comerford, M.; Stokes, M. Assessing movement quality using the hip and lower limb movement screen: Development, reliability and potential applications. J. Musculoskelet. Res. 2019, 22, 1950008. [CrossRef]

6. Cook, G.; Burton, L.; Hoogenboom, B. Pre-participation screening: The use of fundamental movements as an assessment of function-Part 2. N. Am. J. Sports Phys. Ther. 2006, 1, 132-139.

7. Cook, G.; Burton, L.; Hoogenboom, B. Pre-participation screening: The use of fundamental movements as an assessment of function-Part 1. N. Am. J. Sports Phys. Ther. 2006, 1, 62-72.

8. Bonazza, N.A.; Smuin, D.; Onks, C.A.; Silvis, M.L.; Dhawan, A. Reliability, validity, and injury predictive value of the functional movement screen: A systematic review and meta-analysis. Am. J. Sports Med. 2016, 45, 725-732. [CrossRef]

9. Cuchna, J.W.; Hoch, M.C.; Hoch, J.M. The interrater and intrarater reliability of the functional movement screen: A systematic review with meta-analysis. Phys. Ther. Sport 2016, 19, 57-65. [CrossRef] [PubMed]

10. Moran, R.W.; Schneiders, A.G.; Mason, J.; Sullivan, S.J. Do Functional Movement Screen (FMS) composite scores predict subsequent injury? A systematic review with meta-analysis. Br. J. Sports Med. 2017, 51, 1661-1669. [CrossRef]

11. Whittaker, J.; Booysen, N.; De La Motte, S.; Dennett, L.; Lewis, C.L.; Wilson, D.; McKay, C.; Warner, M.; Padua, D.; Emery, C.A.; et al. Predicting sport and occupational lower extremity injury risk through movement quality screening: A systematic review. Br. J. Sports Med. 2016, 51, 580-585. [CrossRef]

12. Zeller, B.L.; McCrory, J.L.; Ben Kibler, W.; Uhl, T.L. Differences in kinematics and electromyographic activity between men and women during the single-legged squat. Am. J. Sports Med. 2003, 31, 449-456. [CrossRef] [PubMed]

13. Bagwell, J.J.; Powers, C.M. The influence of squat kinematics and cam morphology on acetabular stress. Arthrosc. J. Arthrosc. Relat. Surg. 2017, 33, 1797-1803. [CrossRef] [PubMed]

14. Ng, G.K.C.; Mantovani, G.; Lamontagne, M.; Labrosse, M.R.; Beaulé, P.E. Increased hip stresses resulting from a cam deformity and decreased femoral neck-shaft angle during level walking. Clin. Orthop. Relat. Res. 2017, 475, 998-1008. [CrossRef] [PubMed]

15. Bennell, K.; Hunter, D.J.; Vicenzino, B. Long-term effects of sport: Preventing and managing OA in the athlete. Nat. Rev. Rheumatol. 2012, 8, 747-752. [CrossRef]

16. Kerbel, Y.E.; Smith, C.M.; Prodromo, J.P.; Nzeogu, M.I.; Mulcahey, M.K. Epidemiology of Hip and Groin Injuries in Collegiate Athletes in the United States. Orthop. J. Sports Med. 2018, 6, 2325967118771676. [CrossRef] [PubMed]

17. Crow, J.F.; Pearce, A.J.; Veale, J.P.; Van der Westhuizen, D.; Coburn, P.T.; Pizzari, T. Hip adductor muscle strength is reduced preceding and during the onset of groin pain in elite junior Australian football players. J. Sci. Med. Sport 2010, 13, 202-204. [CrossRef]

18. Lovell, G.; Galloway, H.; Hopkins, W.; Harvey, A. Osteitis pubis and assessment of bone marrow edema at the pubic symphysis with MRI in an elite junior male soccer squad. Clin. J. Sport Med. 2006, 16, 117-122. [CrossRef]

19. Whittaker, J.; Woodhouse, L.; Nettel-Aguirre, A.; Emery, C. Outcomes associated with early post-traumatic osteoarthritis and other negative health consequences 3-10 years following knee joint injury in youth sport. Osteoarthr. Cartil. 2015, 23, 1122-1129. [CrossRef]

20. Samar, Z.; Bansal, A. The relationship between self-reported and on field lower extremity functional assessment tools used for assessing functional status in hip dysfunction athletes. Int. J. Sports Sci. 2013, 3, 172-182.

21. Linek, P.; Booysen, N.; Sikora, D.; Stokes, M. Functional movement screen and Y balance tests in adolescent footballers with hip/groin symptoms. Phys. Ther. Sport 2019, 39, 99-106. [CrossRef] [PubMed]

22. Wilson, D.A.; Booysen, N.; Dainese, P.; Heller, M.O.; Stokes, M.; Warner, M.B. Accuracy of movement quality screening to document effects of neuromuscular control retraining exercises in a young ex-footballer with hip and groin symptoms: A proof of concept case study. Med. Hypotheses 2018, 120, 116-120. [CrossRef]

23. Booysen, N.; Wilson, D.; Hawkes, R.; Dickenson, E.; Stokes, M.; Warner, M. Characterising movement patterns in elite male professional golfers using an observational hip and lower limb movement screen. Osteoarthr. Cartil. 2017, 25, S356. [CrossRef]

24. Botha, N.; Warner, M.; Gimpel, M.; Mottram, S.; Comerford, M.; Stokes, M. Movement patterns during a small knee bend test in academy footballers with femoroacetabular impingement (FAI). Health Sci. Work. Pap. 2014, 1, 10.

25. Kazman, J.B.; Galecki, J.M.; Lisman, P.; Deuster, P.A.; O'Connor, F.G. Factor structure of the functional movement screen in marine officer candidates. J. Strength Cond. Res. 2014, 28, 672-678. [CrossRef]

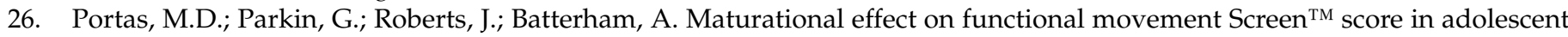
soccer players. J. Sci. Med. Sport 2015, 19, 854-858. [CrossRef] [PubMed]

27. Schober, P.; Boer, C.; Schwarte, L.A. Correlation coefficients. Anesth. Analg. 2018, 126, 1763-1768. [CrossRef] [PubMed]

28. Agresta, C.; Slobodinsky, M.; Tucker, C. Functional Movement Screen ${ }^{\mathrm{TM}}$-Normative values in healthy distance runners. Int. J. Sports Med. 2014, 35, 1203-1207. [CrossRef]

29. Noehren, B.; Davis, I.; Hamill, J. ASB clinical biomechanics award winner 2006: Prospective study of the biomechanical factors associated with iliotibial band syndrome. Clin. Biomech. 2007, 22, 951-956. [CrossRef] [PubMed] 
30. Powers, C.M. The influence of altered lower-extremity kinematics on patellofemoral joint dysfunction: A theoretical perspective. J. Orthop. Sports Phys. Ther. 2003, 33, 639-646. [CrossRef]

31. Lamontagne, M.; Kennedy, M.J.; Beaulé, P.E. The effect of cam FAI on hip and pelvic motion during maximum squat. Clin. Orthop. Relat. Res. 2009, 467, 645-650. [CrossRef] [PubMed]

32. Hammond, C.A.; Hatfield, G.L.; Gilbart, M.K.; Garland, S.J.; Hunt, M.A. Trunk and lower limb biomechanics during stair climbing in people with and without symptomatic femoroacetabular impingement. Clin. Biomech. 2017, 42, 108-114. [CrossRef] [PubMed]

33. Diamond, L.E.; Bennell, K.L.; Wrigley, T.V.; Hinman, R.S.; Hall, M.; O'Donnell, J.; Hodges, P.W. Trunk, pelvis and hip biomechanics in individuals with femoroacetabular impingement syndrome: Strategies for step ascent. Gait Posture 2018, 61, 176-182. [CrossRef] [PubMed]

34. King, M.G.; Lawrenson, P.; Semciw, A.; Middleton, K.; Crossley, K.M. Lower limb biomechanics in femoroacetabular impingement syndrome: A systematic review and meta-analysis. Br. J. Sports Med. 2018, 52, 566-580. [CrossRef]

35. Lewis, C.L.; Loverro, K.L.; Khuu, A. Kinematic differences during single-leg step-down between individuals with femoroacetabular impingement syndrome and individuals without hip pain. J. Orthop. Sports Phys. Ther. 2018, 48, 270-279. [CrossRef] [PubMed]

36. Neal, B.S.; Barton, C.; Gallie, R.; O’Halloran, P.; Morrissey, D. Runners with patellofemoral pain have altered biomechanics which targeted interventions can modify: A systematic review and meta-analysis. Gait Posture 2015, 45, 69-82. [CrossRef]

37. Warner, M.B.; Wilson, D.A.; Herrington, L.; Dixon, S.; Power, C.; Jones, R.; Heller, M.O.; Carden, P.; Lewis, C.L. A systematic review of the discriminating biomechanical parameters during the single leg squat. Phys. Ther. Sport 2019, 36, 78-91. [CrossRef]

38. Sahrmann, S.; Azevedo, D.C.; Van Dillen, L. Diagnosis and treatment of movement system impairment syndromes. Braz. J. Phys. Ther. 2017, 21, 391-399. [CrossRef]

39. Lee, R.Y.; Wong, T.K. Relationship between the movements of the lumbar spine and hip. Hum. Mov. Sci. 2002, 21, 481-494. [CrossRef]

40. Newton, F.; McCall, A.; Ryan, D.; Blackburne, C.; Der Fünten, K.A.; Meyer, T.; Lewin, C.; McCunn, R. Functional movement screen $\left(\mathrm{fms}^{\mathrm{TM}}\right)$ score does not predict injury in English Premier League youth academy football players. Sci. Med. Footb. 2017, 1, 102-106. [CrossRef]

41. Walbright, P.D.; Walbright, N.; Ojha, H.; Davenport, T. Validity of functional screening tests to predict lost-time lower quarter injury in a cohort of female collegiate athletes. Int. J. Sports Phys. Ther. 2017, 12, 948-959. [CrossRef] [PubMed]

42. Bailey, R.; Selfe, J.; Richards, J. The role of the Trendelenburg Test in the examination of gait. Phys. Ther. Rev. 2009, 14, 190-197. [CrossRef]

43. Malloy, P.; Neumann, D.A.; Kipp, K. Hip biomechanics during a single-leg squat: 5 key differences between people with femoroacetabular impingement syndrome and those without hip pain. J. Orthop. Sports Phys. Ther. 2019, 49, 908-916. [CrossRef]

44. Butler, R.J.; Lehr, M.E.; Fink, M.L.; Kiesel, K.B.; Plisky, P.J. Dynamic balance performance and noncontact lower extremity injury in college football players. Sports Health A Multidiscip. Approach 2013, 5, 417-422. [CrossRef]

45. Kang, M.-H.; Kim, G.-M.; Kwon, O.-Y.; Weon, J.-H.; Oh, J.-S.; An, D.-H. Relationship between the kinematics of the trunk and lower extremity and performance on the Y-balance test. PMER 2015, 7, 1152-1158. [CrossRef]

46. Ko, J.; Rosen, A.B.; Brown, C.N. Functional performance deficits in adolescent athletes with a history of lateral ankle sprain(s). Phys. Ther. Sport 2018, 33, 125-132. [CrossRef] [PubMed]

47. McCann, R.S.; Kosik, K.B.; Terada, M.; Beard, M.Q.; Buskirk, G.E.; Gribble, P.A. Associations between functional and isolated performance measures in college women's soccer players. J. Sport Rehabil. 2017, 26, 376-385. [CrossRef] [PubMed]

48. Jensen, U.; Weilbrenner, F.; Rott, F.; Eskofier, B. Sensor-based mobile functional movement screening. In Wireless Mobile Communication and Healthcare; Springer: Berlin/Heidelberg, Germany, 2013; Volume 61, pp. 215-223.

49. Whiteside, D.; Deneweth, J.M.; Pohorence, M.A.; Sandoval, B.; Russell, J.R.; McLean, S.G.; Zernicke, R.F.; Goulet, G.C. Grading the functional movement screen. J. Strength Cond. Res. 2016, 30, 924-933. [CrossRef] [PubMed]

50. Wu, W.-L.; Lee, M.-H.; Hsu, H.-T.; Ho, W.-H.; Liang, J.-M. Development of an automatic functional movement screening system with inertial measurement unit sensors. Appl. Sci. 2020, 11, 96. [CrossRef] 